Tersedia online di: http://ejournal-balitbang.kkp.go.id/index.php/jkpi
e-mail:jkpi.puslitbangkan@gmail.com
JURNAL KEBIJAKANPERIKANANINDONESIA
Volume 12 Nomor 2 November 2020
p-ISSN: 1979-6366
e-ISSN: 2502-6550
Nomor Akreditasi Kementerian RISTEK-BRIN: 85/M/KPT/2020

\title{
PENGEMBANGAN BUDIDAYA KEPITING BAKAU (Scylla sp) SISTEM SILVOFISHERY UNTUK MELESTARIKAN HUTAN BAKAU DI KABUPATEN KEPULAUAN MERANTI PROVINSI RIAU
}

\section{DEVELOPMENT OF MUD CRAB CULTURE (Scylla sp) “SILVOFISHERY SYSTEM" TO PRESERVE MANGROVE FOREST ON THE KEPULAUAN MERANTI DISTRICT, RIAU PROVINCE}

\author{
Budijono $^{1 *}$, Eko Prianto', Muhammad Hasbi ${ }^{1}$ dan Andri Hendrizal ${ }^{1}$ \\ ${ }^{1}$ Dosen Jurusan Manajemen Sumberdaya Perairan, Fakultas Perikanan dan Kelautan, Universitas Riau, Kampus Bina Widya KM. \\ 12,5, Simpang Baru, Kec. Tampan, Kota Pekanbaru, Riau 28293, Indonesia \\ Teregistrasi I tanggal: 04 Agustus 2020; Diterima setelah perbaikan tanggal: 06 Januari 2021; \\ Disetujui terbit tanggal: 13 Januari 2021
}

\begin{abstract}
ABSTRAK
Hutan mangrove merupakan salah satu ekosistem pesisir yang berperan penting dalam mendukung kehidupan biota laut. Keberadaan hutan mangrove di Kabupaten Kepulauan Meranti saat ini terus mengalami degradasi yang berimplikasi terhadap menurunnya fungsi ekologis, sosial dan ekonomi masyarakat lokal. Upaya meminimalisir kerusakan hutan mangrove terus dilakukan oleh pemerintah daerah dan masyarakat lokal hingga saat ini. Salah satu upaya yang dapat dilakukan melalui budidaya kepiting bakau dengan sistem sylvofishery. Metode penelitian yang digunakan adalah eksperimen dan wawancara yang dilakukan di Kelurahan Teluk Belitung dan Desa Bandul Kabupaten Meranti. Data dan informasi dihimpun dari penelusuran, dan penelahaan data dan informasi hasil penelitian serta laporan kegiatan yang terkait dengan budidaya kepiting bakau dengan sistem silvofishery. Hasil kajian menunjukkan potensi pengembangan budidaya laut di Kabupaten Kepulauan Meranti tersebar di beberapa pulau seperti Pulau Padang, Tebing Tinggi dan Pulau Rangsang dengan luas lahan sebesar 438 ha. Luasnya lokasi budidaya didukung pula dengan kualitas perairan yang cukup bagus dan cocok untuk dikembangkan budidaya kepiting dengan sistem sylvofishery. Ujicoba penerapan sylvofishery kepiting bakau model kurungan tancap diperoleh tingkat survival rate mencapai $70 \%$ dan pertumbuhan rata-rata berkisar $100-140 \mathrm{~g}$ per bulan. Pemeliharaan kepiting bakau dengan sistem sylvofishery selama 3 bulan dapat memberikan keuntungan dan tambahan penghasilan per bulan sebesar Rp. 1.070.150. Dalam satu siklus pembesaran jika kondisi normal dapat mengembalikan investasinya sehingga sylvofishery kepiting bakau layak dijadi usaha alternatif bagi masyarakat pesisir.
\end{abstract}

Kata Kunci: Kepiting Bakau; Silvofishery dan Kabupaten Kepulauan Meranti

\begin{abstract}
Mangrove forest is one of the coastal ecosystems were plays a role in supporting marine life. Existence of mangrove forests in the Meranti Kepulauan district is experiencing degradation which has implications for the decline to ecological, social and economic functions of the local community. The efforts for minimize damage of mangrove forests have been carried out by local governments and local communities. One of the effort could be done through the cultivation of mud crabs with sylvofishery system. Experiment method was applied and interview was done in Teluk Belitung and Bandul villages, Meranti Regency. Data and information were collected and had been analyzed and activities reported that related to mud crab culture using the silvofishery system. The resut of the study showed that potential development of marine culture in the Kepulauan Meranti district is spread across several islands such as Padang Island, Tebing Tinggi and Pulau Rangsang with an area of 438 ha. The extent of the aquaculture site is also supported by good waters quality and suitable for developing mud crab culture with the sylvofishery system. The trial application of the
\end{abstract}


mud crab silvofishery model of fixed confinement obtained a survival rate of up to $70 \%$ and an average growth of around 100-140 g per month. Maintenance of mangrove crabs with the sylvofishery system for 3 months can provide benefits and additional income per month of IDR. 1,070,150. In one cycle of enlargement if normal conditions, it's can return the investment so the mangrove crab sylvofishery deserves to be an alternative effort for coastal communities.

\section{Keyword: Mud crab culture; Silvofishery and Kepulauan Meranti district}

\section{PENDAHULUAN}

Hutan mangrove merupakan salah satu ekosistem yang penting dalam membatasi dimensi daratan dan perairan laut yang tersebar di setiap pulau besar dan kecil di Indonesia. Luas potensial hutan mangrove Indonesa sekitar \pm 9.2 juta ha yang terdiri kondisi baik $( \pm 2.5$ juta ha), kondisi rusak sedang $( \pm 4.5$ juta ha) dan kondisi rusak ( \pm 2.1 juta ha) (Vitasari, 2015). Pada tahun 2006 luas hutan mangrove hanya tinggal \pm 4.39 juta ha (Dinas Kehutanan dan Perkebunan, 2007). Kerusakan hutan mangrove juga terjadi di Provinsi Riau, pada tahun 2007 luasnya sebesar \pm 234.5 ribu ha yang dalam 2 dekade telah terjadi penurunan luas sebesar $39 \%$, bahkan saat ini luas mangrove hanya tinggal \pm 143.8 ribu ha (Dinas Kehutanan Provinsi Riau, 2013).

Secara umum kerusakan mangrove di Propinsi Riau disebabkan oleh penebangan yang berlebihan untuk pemenuhan kebutuhan panglong arang maupun kebutuhan bahan bangunan, konversi lahan untuk perluasan pemukiman, industri, pelabuhan maupun lahan budidaya dan pencemaran perairan. Akibat kerusakan tersebut berdampak pada berkurangnya luasan hutan mangrove, hilangnya keanekaragaman hayati, menurunnya hasil tangkapan ikan dan abrasi yang menyebabkan berubahnya garis pantai (Prianto et al, 2006).

Kabupaten Kepulauan Meranti menjadi bagian wilayah Provinsi Riau telah mengalami kerusakan mangrove yang serius seperti di Kelurahan Teluk Belitung Pulau Padang yang kini hanya tertinggal seluas 14,53 ha (2015) dari 299,31 ha pada tahun 2000. Hasil penelitian Umayah et al. (2016) menunjukkan bahwa di Kecamatan Merbau Kabupaten Meranti telah mengalami kerusakan mangrove yang cukup parah dengan total nilai kerapatan hanya 626,67 pohon/ha dan penutupan mangrove pada semua jenis $<50 \%$.

Untuk meminimalisasi kerusakan ekosistem mangrove diperlukan upaya pengelolaan berkelanjutan dengan melibatkan masyarakat lokal. Pengembangan pengelolaan mangrove yang melibatkan masyarakat lokal dalam kawasan tersebut, karena keberadaan masyarakat sekitar hutan mangrove sangat berpengaruh terhadap kelestarian ekosistem hutan mangrove (Wijaya \& Yulianda, 2017). Salah satu upaya meminimalisir kerusakan hutan mangrove dengan cara membangun lapangan usaha yang disinergikan dengan kegiatan konservasi mangrove, salah satunya sistem silvofishery kepiting bakau (Scylla serrata) (Paruntu et al. (2016).

Dalam tulisan ini dibahas tentang potensi dan peluang pengembangan budidaya kepiting bakau dengan sistem silvofishery di Kabupaten Meranti Provinsi Riau. Data dan informasi primer merupakan hasil penelitian yang dilakukan tahun 2019 sedangkan data dan informasi sekunder dihimpun dan ditelusuri serta ditelaah dari hasil penelitian yang telah dilakukan serta laporan kegiatan dari berbagai sumber yang terkait dengan budidaya kepiting bakau dengan sistem silfofishery. Tujuan penulisan ini adalah untuk mengetahui potensi dan peluang pengembangan budidaya kepiting bakau dengan sistem silvofishery di Kabupaten Meranti sebagai mata pencaharian alternatif bagi masyarakat.

\section{BAHASAN \\ Dinamika Pemanfaatan Hutan Mangrove di Kepulauan Meranti}

Luas hutan mangrove di Kabupaten Kepulauan Meranti tahun 2016 mencapai 25.619 ha, dimana 18.300 ha sudah didaftarkan sebagai hutan Tanaman Rakyat (HTR). Hutan bakau yang terdaftar di HTR terletak di Pulau Padang Kecamatan Merbau, sementara sisanya ada di pulau lain dan belum terdaftar. Diketahui bahwa pemanfaatan hutan yang dilakukan secara berlebihan menyebabkan potensi hutan bakau cenderung mengalami pengurangan karena banyak ditebang atau dirambah dan dialih fungsikan menjadi lahan budidaya. Sebagian besar hutan bakau di Kabupaten Kepulauan Meranti, yaitu sekitar 60 persen hutan bakau di kawasan ini hancur akibat pembabatan yang dilakukan tanpa memikirkan dampak lingkungan (Samsuri, 2019).

Salah satu faktor penyebab rusaknya hutan bakau sebagian besar berasal dari aktivitas panglong arang yang jika tidak dikendalikan akan menyebabkan pencemaran lingkungan, potensi abrasi yang terus bertambah, instrusi air laut yang parah, dan dampak lainnya, Jumlah perusahaan panglong arang yang telah memilki izin SPPL sampai dengan september 
2017 adalah 54 perusahaan industri pengolahan arang, yang mana jumlah tersebut menjadi pemicu rusaknya lingkungan hidup hutan bakau.

Menurut Umayah et al., (2016) bahwa vegetasi ekosistem mangrove di Desa Teluk Belitung Kabupaten Kepulauan Meranti telah mengalami perubahan luasan mangrove berdasarkan pengolahan data citra satelit tahun 2000 hingga 2015. Perubahan kawasan ekosistem mangrove dialih fungsikan menjadi kawasan pemukiman, lahan pertanian dan dibiarkan menjadi kawasan semak belukar. Tahun 2000 total luasan ekosistem mangrove sebesar 299,31 ha namun luasan ekosistem mangrove ini mengalami penurunan luasan pada tahun 2005 yaitu 54,47 ha, sedangkan pada tahun 2005-2010 kerusakan ekosistem mangrove tertinggi mencapai 64,96ha, dan pada tahun 2010-2015 mengalami penurunan kerusakan mangrove menjadi 14,53 ha.

Selanjutnya menurut Umayah et al. (2016) bahwa penurunan kerusakan ekosistem mangrove tahun 2010-2015 terjadi karena adanya upaya rehabilitasi mangrove yang dilakukan oleh Pemerintah Kabupaten Kepulauan Meranti. Upaya ini dilakukan untuk mengurangi terjadinya kerusakan mangrove yang disebabkan oleh abrasi maupun pemanfaatan mangrove oleh masyarakat. Upaya rehabilitasi mangrove telah berlangsung pada tahun 2012 dengan melibatkan beberapa kelompok masyarakat yang peduli terhadap kelestarian ekosistem mangrove, namun kesadaran terhadap ekosistem mangrove pada masyarakat umum masih sangat kurang.

\section{Konsep Sylvofishery}

Sylvofishery adalah salah satu konsep kuno dalam pengelolaan sumberdaya pesisir yang mengintegrasikan konservasi mangrove dengan budidaya air payau (Quarto dalam Arifin, 2006). Ini adalah bentuk budidaya perikanan berkelanjutan dengan input yang rendah. Pendekatan terintegrasi ini memungkinkan untuk mengkonservasi dan memanfaatkan sumberdaya mangrove dengan mempertahankan keutuhan mangrove yang relatif lebih tinggi dalam area mangrove, ketika terjadi pembesaran nilai ekonomi pada budidaya air payau (Wijaya, 2011).

Sylvofishery mempunyai potensi dalam menangkap beberapa manfaat ekonomi dari area mangrove dalam kerangka lingkungan yang sensitif dan aktivitas yang berkelanjutan. Perbaikan dalam pengembalian manfaat ekonomi dalam sistem ini akan menjadi faktor kunci dalam penerimaan metode ini secara luas sebagai aktivitas yang berlanjut secara ekonomi dalam mengelola hutan mangrove. Sylvofishery juga menyediakan alternatif aktivitas ekonomi bagi rakyat pedesaan yang miskin dan hal itu mungkin dapat mengurangi tekanan ekologi terhadap hutan mangrove (Arifin, 2006).

Pengembangan silvofishery harus dilaksanakan dengan berdasarkan pada kondisi lingkungan yang khusus dan disesuaikan dengan daya dukung lingkungan. Pengembangan perikanan harus memenuhi kebutuhan dasar masyarakat secara ekonomi dengan tetap memperhatikan kelestarian lingkungan. Pendekatan terintegrasi akan memberikan peluang terhadap aktivitas ekonomi dengan tetap menerapkan program konservasi dan rehabilitasi terhadap ekosistem mangrove (Fitzgerald \& William, 2002).

Dua model dasar sylvofishery yang umum dikembangkan yaitu model empat parit dan model mangrove yang berselang seling (komplangan) (Quarto dalam Arifin, 2006). Budidaya kepiting bakau dapat dilakukan di tambak air payau atau di kurungan tancap di dalam area mangrove (Wijaya et al., 2010). Budidaya kepiting dalam kurungan tancap lebih mendekati model empang parit, karena kurungan tancap kepiting dibangun dalam area rawa mangrove. Mangrove dalam area silvofishery dibiarkan tetap utuh untuk menyediakan lingkungan yang alami agar kepiting dapat tumbuh dan bereproduksi sedangkan parit keliling yang tidak terlalu luas dibuat untuk memenuhi kebutuhan air asin bagi kepiting (Wijaya, 2011). Model silvofishery yang dikembangkan dalam penelitian ini sedikit berbeda dengan model yang lainnya. Model silvofishery yang dikembangkan Kabupaten Meranti ini menambahkan ban mobil sebagai tempat persembunyian kepiting sehingga keberadaannya aman dari predator.

\section{Potensi Pengembangan Sylvofishery}

Kabupaten Kepulauan Meranti merupakan pemekaran dari Kabupaten Bengkalis yang memiliki ekosistem mangrove yang cukup luas. Pada tahun 1991 luas hutan mangrove di Kabupaten Kepulauan Meranti seluas \pm 22.464 ha (Dinas Kehutanan dan Perkebunan, 2007). Luasnya area mangrove di Kabupaten Meranti membuka peluang untuk dikembangkan usaha budidaya kepiting bakau melalui sistem sylvofishery. Potensi pengembangan budidaya laut tersebar di beberapa pulau seperti Pulau Padang, Tebing Tinggi dan Pulau Rangsang (Bappeda Kab. Kepulauan Meranti, 2010) dengan luas lahan sebesar 438 ha. 
Kondisi kualitas air di Kabupaten Meranti secara umum cukup baik dengan rata-rata suhu perairan sebesar $28^{\circ} \mathrm{C}$, salinitas sebesar 25 permil dan $\mathrm{pH}$ perairan sebesar 8 serta memiliki substrat lumpur berpasir dengan ketebalan berkisar $80-100 \mathrm{~cm}$. Menurut Cholik (1999) bahwa suhu yang baik untuk pertumbuhan kepiting bakau yaitu berkisar $28-33^{\circ} \mathrm{C}$ dan Kuntinyo et al. (1994) berpendapat bahwa suhu yang baik untuk budidaya kepiting bakau berkisar antara $26-32^{\circ} \mathrm{C}$, suhu yang terdapat pada perairan mangrove di Kepulauan Meranti tersebut berada pada kisaran yang dapat menunjang siklus hidup kepiting bakau. Selanjutnya menurut Setiawan dan Triyanto (2012), nilai optimal salinitas yang baik untuk menunjang pertumbuhan Scylla serrata berkisar antara 15 - 25 ppt sedangkan menurut Siahainenia (2008) bahwa perairan yang memiliki kisaran $\mathrm{pH}$ 6,5 7,5 dikategorikan perairan yang cukup baik bagi kepiting bakau. Dengan demikian ditinjau dari kualitas perairan di Kabupaten Kepulauan Meranti sangat cocok untuk dikembangkan budidaya kepiting dengan sistem sylvofishery.

Pengembangan sistem sylvofishery memiliki beberapa kelebihan diantaranya: i) kepiting bakau merupakan biota yang secara alami hidup dalam hutan mangrove, sehingga untuk memelihara kepiting bakau tidak perlu mengeluarkan biaya untuk membuka mangrove, cukup dengan membuat pagar yang mengurung biota yang dipelihara, ii) kepiting bakau dipelihara dalam habitat alaminya dan hutan mangrove menyediakan kondisi fisik kimia lingkungan yang sesuai dengan kebutuhan kepiting bakau iii) hutan mangrove menyediakan pakan alami bagi kepiting bakau iv) sistem kurungan ini berfungsi untuk pemeliharaan sementara bagi kepiting yang rendah mutunya hingga menjadi kepiting yang berkualitas ekspor dan v) fungsi ekologis mangrove masih tetap terjaga, karena hutan mangrove tidak ditebang (Triyanto et al., 2012).

\section{Penerapan Sistem Silvofishery}

Sistem sylvofishery kepiting bakau yang cocok dikembangkan di Provinsi Riau adalah pembesaran atau penggemukan dengan mengadopsi model empang parit. Ujicoba penerapan sylvofishery kepiting bakau sistem kurungan tancap telah dilakukan di Desa Tanjung Pasir Kecamatan Tanah Merah Kabupaten Indragiri Hilir dengan hasil pertambahan berat kepiting bakau mencapai 170 g/ekor selama satu bulan pemeliharaan dari berat awal $90 \mathrm{~g}$ dengan tingkat survival rate mencapai 70\% (Balitbang Provinsi Riau dan LPPM Universitas Riau, 2016). Sedangkan untuk daerah Kelurahan Teluk Belitung melalui sistem sylvofishery diperoleh berat kepiting mencapai 425 gram/ekor dari berat awal $150 \mathrm{~g}$. Dilihat dari pertumbuhan dan tingkat kelulushidupan yang tinggi penerapan sistem sylvofishery kepiting bakau sangat menjanjikan.

Konsep pembesaran dalam sistem ini adalah upaya meningkatkan pertumbuhan dan kualitas daging kepiting bakau yang dipasarkan. Pembesaran kepiting bakau ini dapat meningkatkan nilai tambah dan meningkatkan pendapatan serta menumbuhkan lapangan kerja. Oleh sebab itu, potensi pengembangan silvofishery untuk masyarakat di Kabupaten Meranti, dilakukan dengan meramu ekosistem mangrove untuk pembesaran kepiting bakau yang memberdayakan tenaga kerja lokal untuk menghasilkan produk kepiting bakau yang berkualitas baik. Tahapan-tahapan budidaya kepiting bakau sebagai berikut:

\section{a. Membangun Karamba Jaring Tancap}

Model silvofishery yang akan dikembangkan tentu saja harus disesuaikan dengan karakteristik masyarakat diwilayah tersebut, terlebih apabila di wilayah tersebut masyarakat sangat tergantung dengan keberadaan hutan mangrove. Konstruksi keramba jarring tancap tergolong teknologi sangat sederhana yang terbuat dari jaring polyethylene (PE) dan ditopang dengan kayu dan papan. Ukuran mata jaring yang digunakan sebesar \pm 1 inci. Pancang karamba jaring tancap (KJT) dibuat menggunakan kayu mangrove dengan ukuran $5 \mathrm{~m}(\mathrm{P}) \times 5 \mathrm{~m}(\mathrm{~L}) \times 3$ $\mathrm{m}(\mathrm{T})$. Tiang penegak jaring PE sebagai dinding kurungan menggunakan kayu teki sepanjang 4 meter, dimana di bagian pangkal kayu ditancapkan kedalam lumpur sedalam $75-100 \mathrm{~cm}$.

Untuk memperkuat konstruksi, tiap tiang dihubungkan dua keping papan yang dibenamkan kedalam lumpur guna mencegah kepiting keluar dari kurungan. Setelah semua tiang ditegakkan, baru dibentang jaring PE yang telah dipotong, dimana pada bagian bawah dimasukkan kedalam lumpur sesuai kedalaman tiang yang ditancapkan. Penguatan jarring yang dibentangkan digunakan paku 2 inci dan bagian salah satu sisi kurungan dibuat pintu masuk. Di masing-masing kurungan terdapat vegetasi mangrove yang berguna bagi kepiting untuk berlindung, berteduh dari sinar matahari saat surut dan penghasil serasah mangrove).

Pada bagian dinding kurungan dibuat parit keliling dengan lebar $40 \mathrm{~cm}$ dengan kedalaman $20-30 \mathrm{~cm}$ dengan jarak dari dinding sekitar $40 \mathrm{~cm}$. Parit keliling yang dibuat ini dimaksudkan untuk tempat berendamnya kepiting agar tidak mengalami 
kekeringan saat surut, walaupun kepiting ini dapat membuat lubang kedalam lumpur. Selain parit, juga dimasukkan ban bekas mobil untuk kepiting berlindung. Pada bagian depan yang menghadap ke laut, terutama di luar kurungan tancap dibuat turap untuk meredam energi gelombang yang kuat pada saat-saat musim tertentu.

\section{b. Pemeliharaan Benih}

Menurunnya stok induk kepiting bakau alam di Kabupaten Meranti menyebabkan ketersediaan benih di alam juga menurun. Salah satu upaya yang dilakukan melalui pengiriman benih dari kabupaten atau provinsi lain. Benih kepiting bakau yang dibesarkan berasal dari tangkapan di alam diperoleh dari pengepul. Benih berasal dari beberapa perairan, diantaranya Kabupaten Indragiri Hilir Provinsi Riau dan Kabupaten Tanjung Balai Asahan Provinsi Sumatera Utara.

Benih kepiting bakau yang diperoleh dari pengepul, kemudian dipelihara di dalam karamba jaring tancap. Pengembangan KJT di Kabupaten Meranti sangat layak dikembangkan dari segi pendapatan dan keuntungan (Budijono et al., 2019). Pemeliharaan bertujuan untuk membesarkan benih tersebut hingga mencapai ukuran jual yaitu 300-350 g. Ukuran benih yang ditebar rata-rata memiliki bobot $100 \mathrm{~g} / \mathrm{ekor}$ dan pemeliharaan dilakukan selama kurun waktu 2-3 bulan. Jumlah padat tebar disesuaikan dengan luasan $\mathrm{KJT}\left(25 \mathrm{~m}^{3}\right)$ sehingga padat tebar masing-masing KJT sebesar 6 ekor $/ \mathrm{m}^{3}$.

\section{c. Pemberian Pakan}

Pakan yang diberikan berupa ikan rucah segar seperti ikan lomek (Harpadon sp), biang (Ilisha elongata), ikan hiu, siput (beragam gastropoda), udang pepai (Acetes sp) diperoleh dari hasil tangkapan nelayan. Pemberian pakan dilakukan 2 kali/ sehari sebanyak $10 \%$ dari berat total kepiting. Pemberian pakan kepiting dilakukan pada saat air surut dengan cara ditebar. Sebelum diberikan, ikan rucah terlebih dahulu di potong-potong menjadi ukuran yang lebih kecil agar benih kepiting lebih mudah untuk memakannya.

Jenis substrat di sekitar hutan mangrove umumnya terdiri dari lumpur dan tanah liat. Substrat halus banyak mengandung serasah dan bahan organik yang dihasilkan dari daun-daun mangrove yang jatuh ke lumpur sekitar pohon mangrove yang terdekomposisi oleh bakteri, sehingga serasah pada substrat tersebut sangat mendukung bagi makanan organisme tertentu, yaitu organisme pemakan detritus dari kelompok
Gastropoda (Ellobiidae dan Potamididae). Gastropoda diketahui merupakan salah satu makanan alami kepiting bakau. Menurut Opnai (1986), 89\% isi lambung kepiting bakau terdiri atas bivalvia, gastropoda, dan moluska lainnya. Dalam kaitannya dengan kehidupan dan distribusi kepiting bakau, kandungan substrat dasar perairan mangrove merupakan faktor penting yang mempengaruhi kehidupan dan distribusi moluska yang merupakan makanan alami kepiting bakau. Tekstur substrat lumpur oleh kepiting bakau dimanfaatkan untuk bersembunyi, mempertahankan diri agar tetap dingin selama air surut dan melindungi diri dari predator (Tahmid, 2016); (Yulianti \& Sofiana, 2018).

\section{d. Pengelolaan Lingkungan Budidaya}

Guna menghindari benih kepiting terserang penyakit maka secara berkala dilakukan pembersihan KJT dari sampah plastik dan sampah organik lainnya serta menjamin distribusi air saat pasang dan surut agar tetap lancar. Penutupan jarring oleh lumut ini biasanya terjadi setelah kegiatan budidaya telah berjalan beberapa waktu lamanya. Pembersihan waring dilakukan setiap dua minggu sekali agar mata jarring tidak tertutup dengan lumpur atau lumut. Pembersihan jaring dilakukan dengan cara mencucian secara manual pada periode waktu tertentu.

\section{e. Pengukuran Bobot Tubuh}

Untuk mengetahui pertumbuhan kepiting bakau dilakukan pengukuran bobot setiap bulannya. Pengukuran bobot dilakukan melalui sampling terhadap beberapa ekor kepiting yang diambil secara acak. Jumlah kepiting yang ditimbang sebanyak \pm 10 ekor/bulannya. Selama pemeliharaan satu bulan benih kepiting bisa mencapai berat 210-250 g. Jika dibandingkan dengan bobot awal kepiting yang dimasukkan dengan rata-rata $100 \mathrm{~g}$, maka terjadi perubahan berat berkisar $100-140 \mathrm{~g}$ per bulan, walaupun perubahan bobot individu kepiting tidak seragam. Hasil penelitian yang dilakukan oleh Saidah \& Sofia (2016) bahwa usaha pembesaran kepiting bakau menggunakan sistem silvofishery menunjukkan pertumbuhan yang cukup baik dengan penambahan bobot sebesar $113 \mathrm{~g}$ selama 2 bulan pemeliharaan.

\section{f. Pemanenan}

Pemeliharaan kepiting bakau mulai dari benih hingga panen memerlukan waktu sekitar 2-3 bulan dengan ukuran rata-rata mencapai 300-350 g/ekor. Banyaknya jumlah kepiting bakau yang dipanen oleh nelayan pembudidaya berdasarkan pada penerimaan 
pembeli atau permintaan pasar. Sistem pemanenan dilakukan secara masal tanpa melakukan seleksi berdasarkan ukuran, dengan menggunakan serok. Selanjutnya, kepiting bakau diikat capitnya dan dimasukkan ke dalam wadah semi tertutup berupa ember yang diberi lubang, sehingga distribusi dari keramba ke lokasi penjualan dilakukan dalam keadaan hidup.

\section{Analisis Biaya Usaha}

Analisa usaha sylvofishery kepiting bakau di Kabupaten Meranti memberikan keuntungan yang lumayan besar. Biaya yang digunakan dan manfaat yang diperoleh dalam usaha kepiting bakau di Kelurahan Teluk Belitung dikelompokkan kedalam beberapa bagian yaitu: modal investasi, biaya penyusutan dari modal investasi, biaya operasional, penerimaan dan keuntungan.

\section{a. Modal investasi dan biaya Penyusutan}

Modal investasi yang digunakan dalam usaha silvofishery kepiting bakau adalah berupa pengadaan jarring dan peralatan. Dalam suatu usaha biaya penyusutan juga perlu dihitung agar pengeluaran rill usaha dapat tergambar dengan baik. Gray et al. (2005) dalam Shilman (2012) menyatakan bahwa penyusutan merupakan bagian dari benefit proyek yang dicadangkan tiap-tiap tahun sepanjang umur ekonomi proyek sedemikian rupa sehingga merupakan dana yang mencerminkan jumlah biaya modal. Mengenai jenis dan nilai rata-rata modal investasi per unit karamba jaring tangkap dilihat pada Tabel 1.

Tabel 1. Modal Investasi Usaha Silvofishery Kepiting Bakau di Kelurahan Teluk Belitung Kabupaten Meranti Table 1. Investment capital of mangrove crab silvofishery in the Teluk Betung Village, Meranti District

\begin{tabular}{|c|c|c|c|c|c|}
\hline $\begin{array}{c}\text { No/ } \\
\text { Number }\end{array}$ & $\begin{array}{l}\text { Jenis Investasi// } \\
\text { Investment Type }\end{array}$ & $\begin{array}{l}\text { Jumlah/ } \\
\text { Amount }\end{array}$ & $\begin{array}{c}\text { Harga } \\
\text { perunit/ } \\
\text { Price } \\
\text { perunit }\end{array}$ & $\begin{array}{c}\text { Total/Total } \\
\text { (Rupiah/ } \\
\text { IDR) }\end{array}$ & $\begin{array}{c}\text { Biaya } \\
\text { Penyusutan/ } \\
\text { Cost of } \\
\text { Depreciation }\end{array}$ \\
\hline 1. & Jaring Polyethilene (m) & $25 \mathrm{~m}^{2}$ & 30.000 & 750.000 & 75.000 \\
\hline 2. & $\begin{array}{l}\text { Tiang pancang } 4 \quad \mathrm{~m} \\
\text { (buah) }\end{array}$ & 12 & 10.000 & 120.000 & 12.000 \\
\hline 3. & Papan (lembar) & 8 & 20.000 & 160.000 & 16.000 \\
\hline 4. & Keranjang panen (unit) & 1 & 25.000 & 25.000 & 2.500 \\
\hline 5. & Serok (unit) & 1 & 10.000 & 10.000 & 1.000 \\
\hline 6. & Timbangan (unit) & 1 & 100.000 & 100.000 & 10.000 \\
\hline 7. & Cangkul (unit) & 1 & 75.000 & 75.000 & 7.500 \\
\hline 8. & Parang (unit) & 1 & 50.000 & 50.000 & 5.000 \\
\hline 9. & Paku 2 inci (kg) & 0.5 & 30.000 & 30.000 & 3.000 \\
\hline & & & & 1.320 .000 & 132.000 \\
\hline
\end{tabular}

\section{b. Biaya operasional}

Biaya operasional dalam penelitian ini adalah semua sarana produksi habis pakai dalam satu siklus produksi. Biaya operasional pertahun tergantung dari banyaknya siklus yang dilakukan, sehingga proses produksi akan terlaksana. Penetapan harga pada aspek finansial adalah berdasarkan harga pasar yang berlaku, secara aspek finansial jenis dan nilai biaya operasional persiklus dapat dilihat pada Tabel 2.

Tabel 2. Biaya Operasional Usaha Silvofishery Kepiting Bakau di Kelurahan Teluk Belitung Kabupaten Meranti

Table 2. Operational cost of mangrove crab silvofishery in the Teluk Belitung Village, Meranti District

\begin{tabular}{ccccr}
\hline $\begin{array}{c}\text { No/ } \\
\text { Number }\end{array}$ & $\begin{array}{c}\text { Jenis Investasi/ } \\
\text { Investment Type }\end{array}$ & $\begin{array}{c}\text { Jumlah/ } \\
\text { Amount }\end{array}$ & $\begin{array}{c}\text { Harga perunit/ } \\
\text { Price perunit }\end{array}$ & $\begin{array}{c}\text { Total/Total } \\
\text { (Rupiah/IDR) }\end{array}$ \\
\hline 1. & Benih berat 100 g (ekor) & 150 & 6.000 & 900.000 \\
2. & Pakan ikan rucah (kg) & 25 & 5.000 & 125.000 \\
\hline & & & & 1.025 .000 \\
\hline
\end{tabular}

\section{c. Penerimaan dan keuntungan}

Modal investasi yang dikeluarkan sebesar Rp. 1.320.000 untuk pembelian peralatan, biaya penyusutan sebesar Rp. 132.000 sedangkan biaya operasional sebesar Rp. 1.025 .000 sehingga besaran modal yang dikeluarkan mencapai Rp. 2.477.000. Jika mortalitas mencapai $20 \%$, maka dari 150 ekor yang ditebar menjadi 130 ekor yang hidup selama pemeliharaan 3 bulan. Jika harga jual Rp.125.000/kg maka akan diperoleh keuntungan kotor penjualan sebesar Rp.5.687.500, maka keuntungan bersih 
sebesar Rp. 3.210.500. Dari keuntungan bersih tersebut diperkirakan dapat memberikan tambahan penghasilan per bulan sebesar Rp. 1.070.150. Dalam satu siklus pembesaran jika kondisi normal dapat mengembalikan investasinya sehingga sy/vofishery kepiting bakau layak dijadi usaha alternative bagi masyarakat pesisir. Usaha sylvofishery kepiting bakau ini dapat dilakukan sebagai usaha sambilan bagi petani dan nelayan.

\section{KESIMPULAN DAN REKOMENDASI Kesimpulan}

Sistem silvofishery kepiting bakau layak dikembangkan di Kabupaten Meranti sebagai alternatif usaha bagi masyarakat pesisir. Pengembangan budidaya kepiting bakau dapat dikembangkan di Pulau Padang, Tebing Tinggi dan Pulau Rangsang dengan luas lahan sebesar 438 ha. Model usaha silvofishery yang tepat untuk diterapkan di Kabupaten Meranti adalah sistem empang parit. Penerapan teknologi sistem ini sangat sederhana dengan waktu budidaya yang singkat namun mampu memberikan keuntungan sebesar Rp. 1.070 .150 per bulan. Selain memberikan manfaat ekonomi, usaha silvofishery juga mampu menjaga kelestarian hutan mangrove dari kerusakan.

\section{Rekomendasi}

Dalam upaya mendukung pengembangan usaha silvofishery Pemerintah Daerah harus membangun hatchery kepiting bakau guna mendukung usaha tersebut. Mengingat selama ini sumber benih masih berasal dari tangkapan alami dan dari luar Kabupaten Meranti. Selanjutnya, untuk memperkuat pengembangan usaha silvofishery, perlu dilakukan kajian daya dukung kawasan yang dapat dikembangkan usaha silvofishery. Karena hutan mangrove tidak hanya diperuntukan untuk usaha perikanan saja namun juga pariwisata, panglong arang dan perikanan tangkap.

\section{PERSANTUNAN}

Tulisan ini merupakan bagian dari kegiatan Penelitian dan Pengabdian Masyarakat yang berasal dari DIPA Universitas Riau Tahun 2017 dan 2019.

\section{DAFTAR PUSTAKA}

Arifin, Z. (2006). Carrying Capacity Assessment on Mangrove Forest with Special Emphasize on Mud Crab Silvofishery System: A Case Studi in Tanjung Jabung Timur District Jambi Province. [Thesis]. Post Graduate School. Bogor Agricultural University, Bogor.
[Bappeda Kab. Kepulauan Meranti] Badan Perencanaan Pembangunan Daerah, Pemerintah Kabupaten Kepulauan Meranti. (2010). Rencana Tata Ruang Wilayah Kabupaten Kepulauan Meranti 2011-2031. Selatpanjang: Bappeda Kab. Kepulauan Meranti.

Badan Penelitian dan Pengembangan Provinsi Riau dan LPPM Universitas Riau. (2016). Kajian Pengembangan Model Mina Mangrove Sebagai Upaya Pemberdayaan Masyarakat di Pesisir Provinsi Riau. Laporan Penelitian Kerjasama BALITBANG Provinsi Riau dan LPPM Universitas Riau, Pekanbaru.

Budijono., Hasbi, M., \& Simarmata, A. H. (2017). Budidaya Sylvofishery Kepiting Bakau (Scylla serrata) Sistem Kurungan Tancap Di Kelurahan Teluk Belitung Kecamatan Merbau Kabupaten Kepulauan Meranti, Riau. Lembaga Penelitian dan Pengabdian Kepada Masyarakat Universitas Riau. Laporan Kegiatan Pengabdian Masyarakat. 37 hal.

Budijono., Hasbi, M., Purwanto, E \& Harahap, S. (2019). Pemberdayaan Masyarakat Pesisir Desa Bandul Kecamatan Tasik Putri Puyu Melalui Sylvofishery Kepiting Bakau (Scylla serrata). Lembaga Penelitian dan Pengabdian Kepada Masyarakat Universitas Riau. Laporan Kegiatan Pengabdian Masyarakat.

Cholik, F. (1999). Review of mud crab culture research in Indonesia. In mud crab aquaculture and biology. ACIAR Proceedings No.78. Canberra. Australia. 14-20p.

Vitasari, M. (2015). Kerentanan Ekosistem Mangrove terhadap Ancaman Gelombang Ektrim/Abrasi Di Kawasan Konservasi Pulau Dua Banten. BIOEDUKASI, 8(2), 33-36.DOI: 10.20961/ bioedukasi-uns.v8i2.3870

Dinas Kehutanan dan Perkebunan. (2007). Luas Keseluruhan Mangrove di Kabupaten Kepulauan Meranti. Jakarta.

Dinas Kehutanan Provinsi Riau. (2013). Statistik Dinas Kehutanan Provinsi Riau Tahun 2013. Dinas Kehutanan Provinsi Riau. 46 hal.

Fitzgerald., \& William, J. Jr. (2002). Integrated Mangrove Forest and Aquaculture Systems (Silvofisheries) in Indonesia. Food and Agriculture Organization of the United Nations (FAO), the World Bank Group, World Wildlife Fund (WWF), 
and the Network of Aquaculture Centres in AsiaPacific (NACA).

Kuntinyo., Arifin, Z., \& Supratomo T. (1994). Pedoman budidaya kepitingbakau (Scylla serrata) di tambak. Direktorat Jenderal Perikanan, Balai Budidaya Air Payau, Jepara.

Opnai, L. J. (1986). Some aspect of phisiology and ecology of mud crab. S. serrata (Crustacea : Decapoda) in the mangrove system of the Pruari and the Arid Deltas. In Report of the workshop on mangrove ecosystem of asia and hosted by the University of Papua New Guinea. Port Moresby. 117-124.

Paruntu, C. P., Windarto, A. B., \& Mamesah, M. (2016). Mangrove Dan Pengembangan Silvofishery Di Wilayah Pesisir Desa Arakan Kecamatan Tatapaan Kabupaten Minahasa Selatan Sebagai Iptek Bagi Masyarakat. Jurnal LPPM Bidang Sains dan Teknologi, 3(2), 1-25.

Prianto, E., Jhonnerie, R., Firdaus, R., Hidayat, T., \& Miswadi. (2006). Keanekaragaman Hayati dan Struktur Ekologi Mangrove Dewasa di Kawasan Pesisir Kota Dumai - Propinsi Riau. Biodiversitas, 7(4), 327-332.

[RTRW] Rencana Tata Ruang Wilayah. (2018). Buku Rencana Tata Ruang Wilayah Provinsi (RTRWP) Riau 2018-2038. 535 hal.

Samsuri, M. (2019). Pelaksanaan Peraturan Daerah Nomor 11 Tahun 2012 Tentang Pengendalian Kerusakan Hutan Bakau Di Desa Sungai Anak Kamal Kecamatan Merbau Kabupaten Kepulauan Meranti. Program Studi IImu Hukum, Fakultas Syariah dan Hukum, Universitas Islam Negeri Sultan Syarif Kasim Riau. Skripsi. 55 hal.

Saidah, S., \& Sofia, L. A. (2016). Pengembangan Usaha Pembesaran Kepiting Bakau (Scylla spp) Melalui Sistem Silvofishery. Jurnal Hutan Tropis, 4(3):265-272 .

Setiawan, F., \& Triyanto. (2012). Studi kesesuaian lahan untuk pengembangan silvofishery kepiting bakau di Kabupaten Berau, Kalimantan Timur. LIMNOTEK, 19(2):158-165.

Shilman, M. I. (2012). Kajian Penerapan Silvofishery Untuk Rehabilitasi Ekosistem Mangrove Di Desa Dabong Kecamatan Kubu Kabupaten Kubu Raya Provinsi Kalimantan Barat. Sekolah Pasca Sarjana IPB. Skripsi. 126 hal.
Siahainenia L. (2008). Bioekologi kepiting bakau (Scylla spp.) di ekosistem mangove Kabupaten Subang Jawa Barat [Disertasi]. Bogor (ID): IPB.

Tahmid, M. (2016). Kajian Ekologi-Ekonomi Kepiting Bakau (Scylla serrata - Forsskal, 1775) Di Ekosistem Mangrove Teluk Bintan Kabupaten Bintan. Sekolah Pascasarjana Institut Pertanian Bogor. Tesis. 105 hal.

Triyanto; Wijaya, N. I; Widiyanto, T; Yuniarti, I; Setiawan, F \& Lestari, F. S. (2012). Pengembangan Silvofishery Kepiting Bakau (Scylla serrata) Dalam Pemanfaatan Kawasan Mangrove di Kabupaten Berau, Kalimantan Timur. Prosiding Seminar Nasional Limnologi VI Tahun 2012. Hal 739-751.

Umayah, S., Gunawan, H., \& Isda, M. N. (2016). Tingkat Kerusakan Ekosistem Mangrove di Desa Teluk Belitung Kecamatan Merbau Kabupaten Kepulauan Meranti. Jurnal Riau Biologia, 1(4), 2430.

Wijaya, N. I. (2011). Pengelolaan Zona Pemanfaatan Ekosistem Mangrove Melalui Optimasi Pemanfaatan Sumberdaya Kepiting Bakau di Taman Nasional Kutai Kalimantan Timur. Sekolah Pascasarjana IPB. Disertasi. Bogor.

Wijaya, N. I., \& Yulianda, F. (2017). Model Pengelolaan Kepiting Bakau Untuk Kelestarian Habitat Mangrove Di Taman Nasional Kutai Provinsi Kalimantan Timur. Jurnal Manusia \& Lingkungan, 24(2), 55-65. DOI: 10.22146/jml.23079

Wijaya, G. H. (2012). Perencanaan Pembangunan Hutan Kota di Kota Selatpanjang, Kabupaten Kepulauan Meranti, Provinsi Riau. Departemen Konservasi Sumberdaya Hutan dan Ekowisata Fakultas Kehutanan IPB. 58 hal.

Wijaya, N.I., Yulianda, F., Boer, M \& Juwana, S. (2010). Biologi Populasi Kepiting Bakau (Scylla serrata F.) di Habitat Mangrove Taman Nasional Kutai Kabupaten Kutai Timur. Jurnal Oseanologi dan Limnologi di Indonesia, 36(3):443-461.

Yulianti., \& Soafiana, M. S. J. (2018). Kelimpahan Kepiting Bakau (Scylla sp.) di Kawasan Rehabilitasi Mangrove Setapuk, Singkawang. Jurnal Laut Khatulistiwa, 1(1), 25-30. 